SVU- International Journal of Veterinary Sciences, 4(1): 87-96, 2021.

Print ISSN: 2535-1826

\title{
Impacts of Probiotic feeding on Behaviors and Welfare related parameters of Heat Stressed
} Broilers

\section{Eslam Ahmed $^{1}$, Moataz Abdel-Rahman ${ }^{2 *}$, Khaled Ghareeb ${ }^{1}$}

${ }^{1}$ Department of Animal Behavior and Management, Faculty of Veterinary Medicine, South Valley University, Qena, Egypt. ${ }^{2}$ Department of Animal Behavior, Management and Animal wealth, Faculty of Veterinary Medicine, Minia University, Minia, Egypt.

This study was performed to investigate the efficacy of probiotic (PROBAC plus) to counteract the adverse effects of heat stress (32-35oc) on the behaviors and welfare related parameters of broiler chickens. One-hundred and twenty chicks were divided into 4 groups. The first group was control (basal diet), second group was broilers reared at high temperature (basal diet), third group was broilers reared at high temperature and fed probiotic (basal diet + Probiotic) and fourth group was probiotic group (basal diet + probiotic). Behavioral patterns of broilers were recorded at week 4, 5 and 6. At d 42 of age, 10 birds from each group were slaughtered to collect blood samples. Blood films were stained for measuring heterophils / lymphocytes $(\mathrm{H} / \mathrm{L})$ ratio. Serum cortisol was also measured. The overall mean frequency of feeding behavior is significantly $(\mathrm{P}=0.045)$ reduced for birds reared at high temperature (32-35oC) compared with other experimental groups. The overall mean frequency of drinking behavior was significantly $(\mathrm{P}=0.053)$ increased due to higher temperature. Walking behavior was significantly $(\mathrm{P}=0.051)$ decreased for birds reared at higher temperature. Running activity did not significantly $(\mathrm{P}>0.05)$ affected by higher temperature. However, probiotic addition to birds reared under control or high temperature significantly elevated the running activity of broilers $(\mathrm{P}=0.050)$. The mean frequency of shaking is significantly $(\mathrm{P}=0.054)$ lower for heat stressed birds with or without probiotic feeding than control. Moreover, the overall mean frequency of behavioral patterns such as crouching, huddling, standing, stretching, and preening did not show any significant differences between experimental groups $(\mathrm{P}>0.05)$. Heat-stressed birds showed a significant $(\mathrm{P} \leq 0.05)$ elevation of serum cortisol and higher $(\mathrm{P} \leq 0.05) \mathrm{H} / \mathrm{L}$ ratio compared with control birds. In conclusion, probiotic feeding for birds reared at high temperature resulted in a reduced $\mathrm{H} / \mathrm{L}$ ratio and a decreased serum cortisol concentration suggesting that probiotic can be a useful tool to counteract the adverse effects of high temperature rearing.

Keywords: Behavior, Welfare, Broilers, Stress, Probiotic.

DOI: 10.21608/svu.2021.58578.1101 Received: January, 18, 2021 Accepted: March 30, 2021 Published: March 31, 2021 Corresponding Author: Moataz Abdel-Rahman: E-mail: mootazabdelrahman@yahoo.com.

Citation: Ahmed et al., 2021. Impacts of Probiotic feeding on Behaviors and Welfare related parameters of Heat Stressed Broilers. SVU-IJVS 2021, 4(1):87-96.

Copyright: (C) Ahmed et al. This is an open access article distributed under the terms of the creative common attribution license, which permits unrestricted use, distribution and reproduction in any medium provided the original author and source are created.

Competing interest: The authors have declared that no competing interest exists. 


\section{INTRODUCTION}

The poultry industry has become an important economic activity all over the world. In Africa, production of chicken meat was increased in the last years (Sakhatskiy, 2015). In large-scale farms, birds are exposed to stressful conditions leading to serious economic losses. Heat stress is one of the most important environmental stressors challenging poultry production. Nowadays, the adverse impacts of heat stress on poultry health received much attention. Heat stressed birds spent less time for feeding, more time for drinking and panting, stretching their wings, less time for moving or walking, and more time for resting (Mack et al., 2013). Moreover, heat stress increases the cortisol level (Ebrahimzadeh et al., 2012) and elevated the heterophil to lymphocyte ratio (He et al., 2018). The alteration of gut microbiota of birds due to heat stress, was reported (Sugiharto et al., 2017). These alterations of behavior, welfare parameters and health may produce great economic losses in broiler production. Consequently, researchers are working continuously to provide a solution or a useful tool to counteract the negative impacts of heat stress.

Organic poultry farming is going to expand worldwide. In this kind of rearing, probiotics can be used as a growth promoting factor (Sugiharto et al., 2017). The use of these feed additives the performance and productivity through modulation of the gut microbiota which plays a critical role in maintaining host health (Yano et al., 2015). A balanced gut microbiota constitutes an efficient barrier against pathogen colonization, stimulates the immune system of birds (Wang et al., 2018).

Probiotic is defined as "a live microbial feed supplement which beneficially affects the host animal by improving its intestinal microbial balance" (Fuller., 1989). The potential health benefits associated with using probiotic include improved digestion, stimulation of gastro-intestinal tract immunity and increased natural resistance to enteric disease (Lee et al., 2015). It was reported that probiotics have a positive impact on the poultry performance (Mountzouris et al., 2007; Song et al., 2014; Al-Fataftah and Abdelqader, 2014), improve microbial balance and synthesize vitamins (Fuller., 1989), release bacteriocins (Rolfe, 2000), improve feed consumption in broilers (Ahmed et al., 2019) and altering bacterial metabolism (Jin et al., 1997).

However, limited reports are available about the efficacy of probiotic feeding to counteract the adverse impacts of high temperature on the behaviors and welfare of broilers during their rearing. Therefore, the current study was conducted to investigate the effect of probiotic feed additive on the behaviors and welfare of broiler chickens reared at high temperature.

\section{MATERIALS AND METHODS}

\section{Birds and housing}

One hundred twenty (120), 1 d old commercial broiler chicks (Ross 308) were obtained from a commercial hatchery. Birds were randomly divided into 4 groups (30 birds / group). All groups were housed in pens with wood shavings floor.

\section{Diets}

Birds of all groups were fed a commercial diet (Alaaf ALmagd, Alarabia Lell-Alaaf, Quesna, El Monofya, Egypt). Chicks were fed starter diet from 1- $14 \mathrm{~d}$, grower diet from 15- $28 \mathrm{~d}$ and finisher diet 29- $42 \mathrm{~d}$ of age. The birds were fed mash diet ad libitum and given free access to fresh and clean water throughout the experimental period. Diet composition was set according to National Research Council (1994). The basal diet composed of yellow corn, 
soybean meal, corn gluten, soy oil, dicalcium phosphate, limestone, common salt, sodium bicarbonate, vitamins, minerals, choline chloride, DL-Methionine and L-lysine. The chemical composition of the basal diet according to the manufacture is summarized (table 1).

Table 1. Diet chemical composition.

\begin{tabular}{|l|c|c|c|}
\hline & Starter & Grower & Finisher \\
\hline Crude protein (\%) & 23 & 21 & 19 \\
\hline Crude fat (\%) & 5.92 & 6.62 & 6.86 \\
\hline ME (kcal/kg) & 3020 & 3100 & 3200 \\
\hline Crude fiber (\%) & 3.76 & 3.46 & 3.20 \\
\hline
\end{tabular}

Probiotic groups were fed with commercial probiotic mixture (PROBAC plus ${ }^{\circledR}$, Animal Health Care company, Reg. No.: M.O.A.:9948, Cairo, Egypt) (1g / kg diet) from $1 \mathrm{~d}$ old to $42 \mathrm{~d}$ of age. Each gram composed of 20 million of Lactobacillus Acidophilus, Plantarum, Bervis and Bifidobacteria also contains $100 \mathrm{mg}$ of Saccharomyces Cerevisiae. It contains digestive enzymes such as amylase, betaglucanase, hemicillulase and cellulase.

\section{Experimental design}

The present experiment had two main variations; 1) housing temperature and 2) probiotic addition (Ahmed et al. 2019). One-hundred twenty chicks were randomly classified into four groups. The first group had a house temperature of $22 \mathrm{oC}$ and fed basal diet. Second group was broilers reared at high temperature (32-35 oC) and fed basal diet. Third group was broilers reared at high temperature (32-35 oC) and fed with basal diet supplemented with probiotic. Fourth group was housed at $22 \mathrm{oC}$ and was fed basal diet supplemented with a probiotic.

\section{Behavioral observations}

Behavioral observations were recorded at 22 day old and extended up to 40 day old. The behaviors of the chicks were recorded by direct observation using a modified focal sampling technique after modification the method of Martin and Bateson (1993). For all behavioral patterns, five birds from each group were marked with blue dye. The behaviors were observed during the grower and finishing period of rearing; at day 22 and day 26 of week 4, at day 29 and day 33 of week 5 and at day 36 and day 40 of week 6. During the days of observations, the behavioral patterns were recorded three times daily as follow; at early morning (7:00-7:30 am), at afternoon (1:00-1:30 pm) and at evening (8:00-8:30 pm). The behavioral patterns were classified as described previously (Lehner, 1992).

\section{Feeding and drinking behavior}

Frequency of pecking at feed on feed trough (number of bouts (n) / bird / $30 \mathrm{~min}$ ) and number of drinking bouts / bird / $30 \mathrm{~min}$ were measured.

\section{Resting behavior}

Frequency of crouching behavior: lying or sitting with breast on the floor, looking around with or without closed eyes ( $\mathrm{n} /$ bird ( 30 min).

Frequency of huddling behavior: huddling means that three or more birds overlapped on each other in a crouching position.

\section{Movement activities}

Frequency of standing ( $\mathrm{n} / \mathrm{bird} / 30 \mathrm{~min}$ ), walking frequency ( $/$ bird / $30 \mathrm{~min}$ ) and rapid running frequency ( $\mathrm{n} / \mathrm{bird} / 30 \mathrm{~min}$ ) were recorded.

\section{Comfort behavior}


Frequency of stretching of legs or wings, shaking, and preening ( $/$ bird / $30 \mathrm{~min}$ ) were recorded.

\section{Slaughtering and blood collection}

At 42 day old, $3 \mathrm{ml}$ of blood were collected from each bird in heparinized tubes ( 5 birds / group) during slaughtering. Blood film was performed directly (two replicates from each bird for differential leucocyte counts. Moreover, another $3 \mathrm{ml}$ of blood were collected in tubes without anticoagulant from the same birds for serum separation.

\section{Heterophils (H), Lymphocytes (L), and H / $\mathrm{L}$ ratio}

Blood films were air dried then fixed with 97\% methanol and stained with Giemsa stain (1:9) for $15 \mathrm{~min}$ (Robertson and Maxwell, 1990). Number of heterophils (H) and lymphocytes (L) were counted using light microscope based on 100 cells. The $\mathrm{H}$ / $\mathrm{L}$ ratio was calculated by dividing the number of heterophils to the number of lymphocytes (Gross and Siegel, 1983). Lymphocytes (figure 1) were regular round cells with a central or slightly eccentric nuclei, and with a varying amount of pale blue cytoplasm by modified WrightGiemsa stain (Clark et al., 2009). Heterophils (figure 2) were characterized by brick red, elongated intracytoplasmic granules and bilobed nuclei by modified Wright-Giemsa stain (Clark et al., 2009).

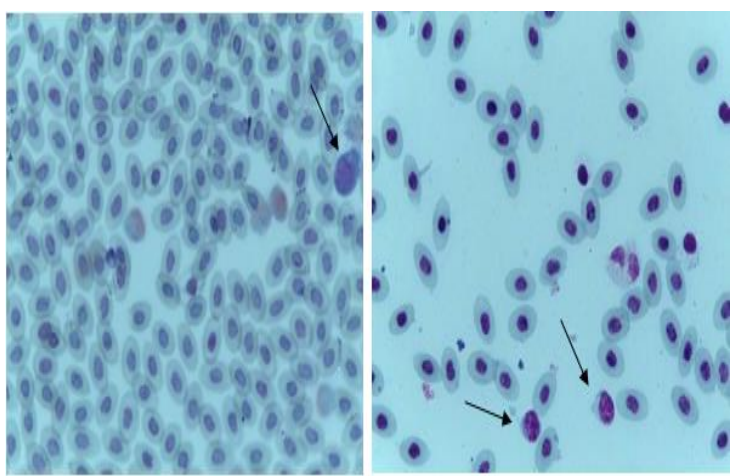

Figure 1. Black arrow refers to Lymphocytes

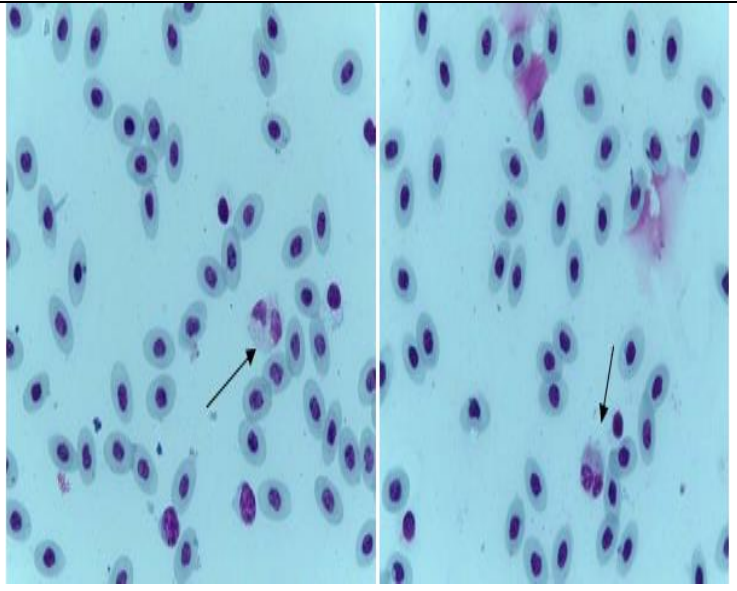

Figure 2. Black arrow refers to Heterophils

\section{Measurement of cortisol hormone}

Serum cortisol level was determined by automatic immunoassay analyzer (chemiluminescence in ARCHITECT 1000SR $®$, Abbott, USA) through using stat fax-2100 (Awareness technology, INC, USA).

\section{Statistical analysis}

Data of the overall mean frequency of each behavioral pattern observed along the observation period ( 5 birds for 3 hours on week 3, 4 and 5 of age), cortisol hormone, Heterophils count, Lymphocytes count, and $\mathrm{H} / \mathrm{L}$ ratio were statistically analyzed using statistical program SPSS version 23. Oneway analysis of variance (ANOVA) was used followed by Duncan test to find the significance between experimental groups. A level of probability $(\mathrm{P})$ of $\leq 0.05$ was considered significant.

\section{RESULTS}

\section{Behavioral patterns}

The overall mean frequency for each behavioral pattern of the observed birds from each experimental group is presented in table 2. The results of this pilot study on the behaviors of broilers reared at high temperature can give us an indication about the disturbances in the behaviors of birds. The overall mean frequency of feeding is 
significantly $(\mathrm{P}=0.045$, table 2$)$ reduced for birds reared at high temperature $(32-35 \mathrm{oC})$ compared with other experimental groups. Opposite to this, the overall mean frequency of drinking bouts was significantly $(\mathrm{P}=$ 0.053 , table 2) increased due to higher temperature. However, addition of probiotic to diet of birds reared under high temperature could not counteract the adverse impacts of heat stress $(\mathrm{P}>0.05$, table 2). Probiotic addition to diet of broilers reared at temperature of $22 \mathrm{oC}$ did not adversely impact feeding and drinking behaviors $(\mathrm{P}>0.05$, table 2$)$.

Walking frequency was significantly decreased $(\mathrm{P}=0.051$, table 2$)$ for birds reared at higher temperature. Addition of probiotic to the diet of high temperature reared broilers did not remove the effect of heat stress on walking behavior $(\mathrm{P}>0.05$, table 2). Nevertheless, probiotic addition alone did not adversely affect the walking activity of broilers $(\mathrm{P}>0.05$, table 2) compared with control birds.

Running as another movement behavioral activity, did not significantly $(\mathrm{P}>0.05$, table 2) affected by higher temperature. However, probiotic addition to birds reared under control or high temperature significantly $(\mathrm{P}=0.050$, table 2$)$ elevated the running activity of broilers.

In contrast, the mean frequency of shaking is significantly lower $(\mathrm{P}=0.054$, table 2$)$ for heat stressed birds with or without probiotic feeding than control. Moreover, the overall mean frequency of behavioral patterns such as crouching, huddling, standing, stretching, and preening did not show any significant differences between experimental groups $(\mathrm{P}>0.05$, table 2$)$.

\section{Stress parameters}

Rearing broilers at high temperature broilers led to a higher $(\mathrm{P} \leq 0.050) \mathrm{H} / \mathrm{L}$ ratio $(0.70 \pm 0.09$, table 3$)$ compared with control birds $(0.20 \pm 0.03)$. However, addition of probiotic to diet of heat stressed birds resulted in a lower $(\mathrm{P} \leq 0.050) \mathrm{H} / \mathrm{L}$ ratio $(0.32 \pm 0.06)$ compared with heat stressed birds $(0.70 \pm 0.09)$.

Table 2. The overall mean frequency of behaviors of broiler chickens during grower and finishing periods of rearing

\begin{tabular}{|c|c|c|c|c|c|}
\hline Behavior & $\begin{array}{l}\text { Control } \\
\text { group }\end{array}$ & $\begin{array}{l}\text { Heat stress } \\
\text { group }\end{array}$ & $\begin{array}{c}\text { Heat stress } \\
\text { plus } \\
\text { probiotic }\end{array}$ & $\begin{array}{c}\text { Probiotic }{ }^{2} \\
\text { group }\end{array}$ & $\begin{array}{c}\mathrm{P} \\
\text { value }\end{array}$ \\
\hline Feeding & $18.94 \pm 2.28^{\mathrm{a}}$ & $11.22^{6} \pm 1.77$ & $14.11^{b} \pm 1.78$ & $14.50^{6} \pm 1.68$ & 0.045 \\
\hline Drinking & $12.94^{b} \pm 1.85$ & $16.05^{5} \pm 1.67$ & $17.00^{\mathrm{a}} \pm 1.59$ & $14.33^{\mathrm{a}} \pm 1.61$ & 0.053 \\
\hline Crouching & $21.22 \pm 2.07$ & $22.22 \pm 2.88$ & $18.94 \pm 2.20$ & $21.05 \pm 1.98$ & 0.773 \\
\hline Huddling & $9.22 \pm 1.64$ & $8.22 \pm 0.81$ & $7.00 \pm 0.95$ & $8.55 \pm 0.82$ & 0.556 \\
\hline Standing & $17.44 \pm 2.41$ & $24.22 \pm 2.61$ & $20.77 \pm 2.82$ & $19.22 \pm 2.03$ & 0.269 \\
\hline Walking & $19.22^{2} \pm 2.97$ & $15.05^{5} \pm 2.76$ & $11.72^{b} \pm 1.68$ & $18.44^{3} \pm 2.85$ & 0.051 \\
\hline Running & $0.55^{b} \pm 0.25$ & $0.66^{b} \pm 0.32$ & $1.22^{\mathrm{a}} \pm 0.59$ & $2.05^{a} \pm 0.60$ & 0.050 \\
\hline Stretching & $8.27 \pm 1.41$ & $9.00 \pm 1.59$ & $10.83 \pm 2.76$ & $12.11 \pm 2.19$ & 0.548 \\
\hline Shaking & $5.27^{a} \pm 3.39$ & $2.05^{b \pm} 0.60$ & $0.94^{b} \pm 0.34$ & $2.55^{\mathrm{a} \pm} 0.63$ & 0.054 \\
\hline Preening & $28.11 \pm 3.58$ & $26.61 \pm 3.78$ & $30.22 \pm 3.87$ & $29.77 \pm 2.87$ & 0.894 \\
\hline
\end{tabular}

a,b,c,d Values within the same row with different letters are significantly different $(P \leq 0.05)$.

${ }^{1}$ Heat stress $\left(32-35^{\circ} \mathrm{C}\right)$ from fourth to sixth week of age. ${ }^{2}$ Probiotic (PROPAC plus ${ }^{\circledR} 1 \mathrm{~g} / \mathrm{kg}$ feed) from $\mathrm{d} 1$ to $\mathrm{d} 42$ of age.

Moreover, rearing at higher temperature produced a significant elevation $(\mathrm{P} \leq 0.050)$ for cortisol level $(1.37 \pm 0.06 \mu \mathrm{g} / \mathrm{dl})$ compared with control birds $(0.88 \pm 0.09$ $\mu \mathrm{g} / \mathrm{dl})$. However, addition of probiotic to diet of heat stressed broilers significantly decreased $(\mathrm{P} \leq 0.050)$ the cortisol concentration $(1.06 \pm 0.05 \mu \mathrm{g} / \mathrm{dl})$ compared with heat stressed broilers alone $(1.37 \pm 0.06$ $\mu \mathrm{g} / \mathrm{dl})$. 
Table 3. Stress parameters of broilers fed with or without probiotic and reared either with or without stress.

\begin{tabular}{|ccccccc|}
\hline Parameters & $\begin{array}{c}\text { Control } \\
\text { group } \\
(\mathrm{n}=5)\end{array}$ & $\begin{array}{c}\text { Heat stress } \\
\text { group } \\
(\mathrm{n}=5)\end{array}$ & $\begin{array}{l}\text { Heat stress } \\
\text { Plus, } \\
\text { probiotic } \\
(\mathrm{n}=5)\end{array}$ & $\begin{array}{c}\text { Probiotic }^{2} \\
\text { group }^{2} \\
(\mathrm{n}=5)\end{array}$ & $\begin{array}{c}\mathrm{P} \\
\text { Value }\end{array}$ \\
\hline $\begin{array}{c}\text { Heterophils } \\
\text { number }\end{array}$ & $18.00 \pm 2.84^{\mathrm{c}}$ & $40.60 \pm 3.28^{\mathrm{a}}$ & $32.80 \pm 4.28^{\mathrm{b}}$ & $18.00 \pm 2.12^{\mathrm{c}}$ & 0.001 \\
$\begin{array}{c}\text { Lymphocytes } \\
\text { number }\end{array}$ & $82.00 \pm 2.84^{\mathrm{a}}$ & $59.40 \pm 3.37^{\mathrm{d}}$ & $67.20 \pm 4.28^{\mathrm{b}}$ & $82.00 \pm 2.12^{\mathrm{a}}$ & 0.001 \\
$\begin{array}{c}\mathrm{H} / \mathrm{L} \\
\text { Ratio }\end{array}$ & $0.20 \pm 0.03^{\mathrm{c}}$ & $0.70 \pm 0.09^{\mathrm{a}}$ & $0.32 \pm 0.06^{\mathrm{b}}$ & $0.22 \pm 0.03^{\mathrm{c}}$ & 0.001 \\
$\begin{array}{c}\text { Cortisol } \\
(\mu \mathrm{g} / \mathrm{dl})\end{array}$ & $0.88 \pm 0.09^{\mathrm{c}}$ & $1.37 \pm 0.06^{\mathrm{a}}$ & $1.06 \pm 0.05^{\mathrm{b}}$ & $0.66 \pm 0.05^{\mathrm{d}}$ & 0.001 \\
\hline \hline
\end{tabular}

a,b,c,d Values within the same row with different letters are significantly different $(P \leq 0.05)$.

${ }^{1}$ Heat stress $\left(32-35^{\circ} \mathrm{C}\right)$ from fourth to sixth week of age. ${ }^{2}$ Probiotic (PROPAC plus ${ }^{\circledR} 1 \mathrm{~g} / \mathrm{kg}$ feed) from $\mathrm{d} 1$ to $\mathrm{d} 42$ of age.

\section{DISCUSSION}

The impacts of high temperature on the health and productivity of broilers were widely studied. However, its effects on behaviors and welfare indices of broilers are still to be investigated. Additionally, the possibility of probiotic feeding to overcome these adverse effects need to be evaluated. Therefore, this study was conducted to study the efficiency of probiotic for counteracting the adverse effects of rearing broilers at high temperature on the behaviors and welfare parameters of broilers.

In our previous paper, rearing of broiler at high temperature led to lowered performance (Ahmed et al., 2019). This deteriorated performance of stressed birds due to high temperature may be due to the adverse effects on behaviors and welfare of broilers. The current study highlighted these adverse impacts of higher temperature on behavior and welfare of broilers. In the present study, high temperature reduced the feeding behavior. The reduction of feeding behavior may be due to reduced appetite for diminishing metabolic heat production (Syafwan et al., 2012). The same result was shown previously due to high temperature rearing (Wang et al., 2018). Not only feeding behavior was affected but also, walking was decreased in the present experiment to reduce or adapt heat stimulation (Mack et al., 2013; Wang et al., 2018). Drinking behavior was significantly higher for birds reared under higher temperature in our current study. This is online with previous studies (May and Lott, 1992; Mahmoud, 2010; Mack et al., 2013). The results of this experiment provide a valuable information on the impacts of higher temperature on welfare parameters. Heat stress resulted in important physiological stress responses in terms of higher $\mathrm{H} / \mathrm{L}$ ratio and higher cortisol concentration. The reason behind that is the alteration of immunity of birds due to activation of the hypothalamic-pituitaryadrenal (HPA) axis which in turn leads to secretion of cortisol from pituitary gland. Similar results were previously recorded (Ebrahimzadeh et al., 2012; Norain et al., 2013; He et al., 2018). These alterations in the behavioral patterns of broilers reared at high temperature adversely affected the performance and health of birds (Ahmed et al., 2019).

Probiotic is widely used as a natural feed additive to improve the performance and immunity of birds. The improved performance of birds in our previous publication (Ahmed et al., 2019) can be explained by an improvement effect of probiotic on behaviors of broilers specially the feeding behavior. In the current study, probiotic feeding enhanced significantly the feeding behavior of heat stressed broilers. Similarly, Mohammed et al. (2018) found that symbiotic is beneficial to overcome the adverse effects of heat stress in broilers. Additionally, Wang et al. (2018) found an increase of foraging and feeding behaviors of heat stressed birds supplemented with probiotic. They attributed the improvement of the feeding behavior to the improved 
appetite of probiotic-supplemented birds. Others found that probiotic supplementation overcame the negative impacts of heat stress on movement activities and comfort-related behaviors as stressed birds fed with probiotic increased their movement activities and increased the frequency of preening and stretching of leg and / or wing (Fayed, R. H., and M.A.Tony, 2008; El Iraqi and Fayed, 2012).

The higher running activity of probiotic group in the current experiment may be due to an improvement of musculoskeletal system with probiotic supplementation. Other researchers reported also the same effects (Narasimha et al., 2013; Yan, 2016; Wang et al., 2018).

Interestingly, the results of the current experiment provide also another important information concerning probiotic supplementation as anti-stress. In the present study, higher temperature rearing resulted in a higher circulating cortisol and higher $\mathrm{H} / \mathrm{L}$ ratio. However, probiotic feeding to heat stressed broilers counteracted these adverse impacts on these welfare parameters. Probiotic feeding to heat stressed broiler or even for control rearing led to low cortisol and lower H/L ratio as the main indicators of stress. Probiotic supplementation to the diet of heat stressed birds removed the adverse effect on welfare parameters. It is obvious in the current study that, probiotic feeding decreased the cortisol level of heat stressed birds. Probiotic bacteria may indirectly stimulate the afferent neurons through a cytokine neurohumoral route, causing a reduction in the levels of circulating corticosterone and Adrenocorticotropic hormone (ACTH) (Gareau et al., 2007). Additionally, probiotic feeding improved the gut health and microbiome and led to a healthy and balanced microbial community and normalize the adrenal gland activity (Lei et al. 2013). Also, Haldar et al. (2011) reported that dietary supplementation of yeast, yeast protein concentrate, and yeast protein concentrate-pellets reduced serum cortisol concentration both at 21 and $35 \mathrm{~d}$ of age when fed to heat stressed birds. Moreover, in the present experiment probiotic reduced significantly the $\mathrm{H} / \mathrm{L}$ ratio. Similar reduction of $\mathrm{H} / \mathrm{L}$ ratio was also recorded previously due to probiotic feeding (Beski and Al-Sardary, 2014; Wang et al., 2018).

Taken together, it can be concluded that rearing of broilers at the environmental temperature of $32-35 \mathrm{oC}$ led to alterations in behaviors, higher $\mathrm{H} / \mathrm{L}$ ratio and an increased level of cortisol suggesting an impairment of welfare of broiler chickens. In addition, probiotic feeding counteracted these adverse impacts of higher temperature rearing of broilers resulting in an improvement of their health, welfare and productivity.

\section{CONFLICT OF INTEREST}

The authors declare that they do not have any conflict of interest.

\section{REFERENCES}

Ahmed, E., Abdelrahman, M. and

Gahreeb, K. (2019). Effect of

Probiotic on Growth Performance, Carcass Traits, and Clinical Health Parameters of Broilers Reared under Heat Stress in Upper Egypt. SVU-International Journal of Veterinary Sciences, vol. 2, no. 2, pp. 27-44.

Al-Fataftah, A.-R. and Abdelqader, A. (2014). Effects of dietary Bacillus subtilis on heat-stressed broilers performance, intestinal morphology and microflora composition. 
Animal feed science and

technology, vol. 198, pp. 279-285.

Beski, S. and Al-Sardary, S. (2014).

Effects of Dietary Supplementation of Probiotic and Synbiotic on Broiler Chickens Hematology and Intestinal Integrity. International Journal of Poultry Science, vol. 14, no. 1, pp. 31-36.

Clark, P., Boardman, W. and Raidal, S. (2009). Atlas of clinical avian hematology, Oxford, New York, Wiley-Blackwell.

Ebrahimzadeh, S. K., Farhoomand, P. and Noori, K. (2012). Immune

Response of Broiler Chickens Fed Diets Supplemented with Different Level of Chromium Methionine under Heat Stress Conditions. Asian-Australasian journal of animal sciences, vol. 25 , no. 2 , pp. 256-260.

El Iraqi, K. G. and Fayed, R. H. (2012). Effect of yeast as feed supplement on behavioural and productive performance of broiler chickens. Life Sci J, vol. 9, pp. 4026-4031.

Fayed, R. H., and M.A.Tony, ed. (2008). Effect of Probiotic

Supplementation As An Anti-Stress Factor On Growth Performance, Behaviour And Carcass Traits Of Broiler Chickens. 1st Mediterreanen Summit, porto carras, Greece.

Fuller., R. (1989). Probiotics in man and animals. Journal of applied bacteriology, vol. 66, no. 5, pp. 365-378.
Gareau, M. G., Jury, J., MacQueen, G., Sherman, P. M. and Perdue, M. H. (2007). Probiotic treatment of rat pups normalises corticosterone release and ameliorates colonic dysfunction induced by maternal separation. Gut, vol. 56, no. 11, pp. 1522-1528.

Gross, W. B. and Siegel, H. S. (1983).

Evaluation of the heterophil/lymphocyte ratio as a measure of stress in chickens. Avian diseases, vol. 27, no. 4, pp. 972-979.

Haldar, S., Ghosh, T., Toshiwati and Bedford, M. (2011). Effects of yeast (Saccharomyces cerevisiae) and yeast protein concentrate on production performance of broiler chickens exposed to heat stress and challenged with Salmonella enteritidis. Animal feed science and technology, vol. 168, 1-2, pp. 6171.

He, S. P., Arowolo, M. A., Medrano, R. F., Li, S., Yu, Q. F., Chen, J. Y. and He, J. H. (2018). Impact of heat stress and nutritional interventions on poultry production. World's Poultry Science Journal, vol. 74, no. 4, pp. 647-664.

Jin, L. Z., Ho, Y. W., Abdullah, N. and Jalaludin, S. (1997). Probiotics in poultry: modes of action. World's Poultry Science Journal, vol. 53, no. 4, pp. 351-368.

Lee, K.-W., Kim, D. K., Lillehoj, H. S., Jang, S. I. and Lee, S.-H. (2015). Immune modulation by Bacillus subtilis-based direct-fed microbials in commercial broiler chickens. 
Animal feed science and technology, vol. 200, pp. 76-85.

Lehner, P. N. (1992). Sampling methods in behavior research. Poultry science, vol. 71, no. 4, pp. 643-649.

Lei, K., Li, Y. L., Yu, D. Y., Rajput, I. R. and Li, W. F. (2013). Influence of dietary inclusion of Bacillus licheniformis on laying performance, egg quality, antioxidant enzyme activities, and intestinal barrier function of laying hens. Poultry science, vol. 92, no. 9, pp. 2389-2395.

Mack, L. A., Felver-Gant, J. N., Dennis, R. L. and Cheng, H. W. (2013). Genetic variations alter production and behavioral responses following heat stress in 2 strains of laying hens. Poultry science, vol. 92, no. 2, pp. 285-294.

Mahmoud, U. T. (2010). Studies on some behavioral patterns of quails with special reference to the effect of heat stress on behaviors, performance and some blood parameters. Master Thesis. Faculty of Veterinary Medicine, Assiut University, Egypt.

Martin, P. R. and Bateson, P. P. G. (1993). Measuring behaviour: An introductory guide, 2nd edn, Cambridge England, New York NY USA, Cambridge University Press.

May, J. D. and Lott, B. D. (1992). Feed and water consumption patterns of broilers at high environmental temperatures. Poultry science, vol. 71, no. 2, pp. 331-336.
Mohammed, A. A., Jacobs, J. A.,

Murugesan, G. R. and Cheng, $\mathrm{H}$. W. (2018). Effect of dietary synbiotic supplement on behavioral patterns and growth performance of broiler chickens reared under heat stress. Poultry science, vol. 97, no. 4, pp. 1101-1108.

Mountzouris, K. C., Tsirtsikos, P., Kalamara, E., Nitsch, S., Schatzmayr, G. and Fegeros, K. (2007). Evaluation of the efficacy of a probiotic containing Lactobacillus, Bifidobacterium, Enterococcus, and Pediococcus strains in promoting broiler performance and modulating cecal microflora composition and metabolic activities. Poultry science, vol. 86, no. 2, pp. 309317.

Narasimha, J., Nagalakshmi, D., Ramana Reddy, Y. and Viroji Rao, S. T. (2013). Synergistic effect of non starch polysaccharide enzymes, synbiotics and phytase on performance, nutrient utilization and gut health in broilers fed with sub-optimal energy diets. Veterinary World, vol. 6, no. 10.

National Research Council (1994). Nutrient Requirements of Poultry, Washington, D.C., National Academies Press

Norain, T. M., Ismail, I. B., Abdoun, K. A. and Al-Haidary, A. A. (2013).

Dietary Inclusion of Chromium to Improve Growth Performance and Immune-Competence of Broilers Under Heat Stress. Italian Journal of Animal Science, vol. 12, no. 4, e92. 
Robertson, G. W. and Maxwell, M. H. (1990). Modified staining techniques for avian blood cells. British poultry science, vol. 31, no. 4, pp. 881-886.

Rolfe, R. D. (2000). The role of probiotic cultures in the control of gastrointestinal health. The Journal of nutrition, vol. 130, 2S Suppl, 396S-402S.

Sakhatskiy, M. I. (2015) Broiler meat production in the world [Online]. Available at http://texha.com/en/presscenter/articles/broiler-meatproduction-in-the-world.htm.

Song, J., Xiao, K., Ke, Y. L., Jiao, L. F., Hu, C. H., Diao, Q. Y., Shi, B. and Zou, X. T. (2014). Effect of a probiotic mixture on intestinal microflora, morphology, and barrier integrity of broilers subjected to heat stress. Poultry science, vol. 93, no. 3, pp. 581588.

Sugiharto, S., Yudiarti, T., Isroli, I., Widiastuti, E. and Kusumanti, E. (2017). Dietary supplementation of probiotics in poultry exposed to heat stress - a review. Annals of animal science, vol. 17, no. 3, pp. 591-604.

Syafwan, S., Wermink, G. J. D., Kwakkel, R. P. and Verstegen, M. W. A. (2012). Dietary self-selection by broilers at normal and high temperature changes feed intake behavior, nutrient intake, and performance. Poultry science, vol. 91, no. 3, pp. 537-549.
Wang, W. C., Yan, F. F., Hu, J. Y., Amen, O. A. and Cheng, H. W. (2018). Supplementation of Bacillus subtilis-based probiotic reduces heat stress-related behaviors and inflammatory response in broiler chickens. Journal of animal science, vol. 96, no. 5, pp. 16541666.

Yan, F. (2016). The effects of dietary probiotic inclusion on skeletal health of poultry and its possible mechanisms. PhD Thesis. Purdue University, USA. Available on https://docs.lib.purdue.edu/open_ac cess_dissertations/1033/

Yano, J. M., Yu, K., Donaldson, G. P., Shastri, G. G., Ann, P., Ma, L., Nagler, C. R., Ismagilov, R. F., Mazmanian, S. K. and Hsiao, E. Y. (2015). Indigenous bacteria from the gut microbiota regulate host serotonin biosynthesis. Cell, vol. 161, no. 2, pp. 264-276. 